\title{
NOVEL PROCESSING OF HTS BASED CONDUCTORS
}

DE90 005956

D. S. GINLEY*, E. L. VENTURINI*, J. F. KWAK*, R. J. BAUGHMAN*, R. J. BOURCIER*, M. A. MITCHELL*, B. MOROSIN*, J. W. HALLORAN**, M. J. NEAL**, and D. W. CAPONE***

*Sandia National Laboratories, Albuquerque, NM 87185 **CPS Superconductor Milford, MA

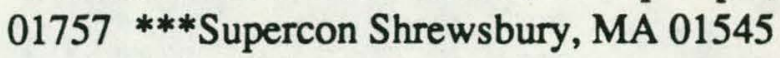

\section{Abstract}

Conductor development is one of the major long term goals in high temperature superconductor research. In this paper we report on two promising processing technologies that have been utilized to produce superconducting $\mathrm{HTS}$ conductors. First, melt spun $\mathrm{YBa}_{2} \mathrm{Cu}_{3} \mathrm{O}_{7}$ fibers rapid thermal processed for $1-8 \mathrm{sec}$ at 950 to $1075^{\circ} \mathrm{C}$ have $\mathrm{T}_{\mathrm{c}}$ 's to $92 \mathrm{~K}, \mathrm{~J}_{\mathrm{c}}$ 's to $1100 \mathrm{~A} / \mathrm{cm}^{2}$ and the orthorhombic twinned morphology typical for high quality $\mathrm{YBa}_{2} \mathrm{Cu}_{3} \mathrm{O}_{7}$. A processing matrix of time, temperature and composition for these fibers shows that slightly CuO-rich starting compositions give the best results. Second, silver tube encapsulated wires of $\mathrm{Bi}_{1.7} \mathrm{~Pb}_{0.3} \mathrm{Sr}_{2} \mathrm{Ca}_{2} \mathrm{Cu}_{3} \mathrm{O}_{10}$ have been made by extrusion, wire drawing and cold rolling. The resulting tapes show orientation of the crystallites, zero resistance up to $100 \mathrm{~K}$ and improved magnetic hysteresis above $50 \mathrm{~K}$. The combination of mechanical reprocessing and extended thermal anneals near $850^{\circ} \mathrm{C}$ appears to significantly improve these materials.

\section{Introduction}

The development of high current conductors from high temperature superconductors that can operate in high magnetic fields remains the greatest challenge in HTS research. To accomplish this, three major obstacles will have to be overcome. First is the brittle ceramic nature of the materials, which will necessitate composite structures to ensure mechanical and electrical integrity. Second is the weak link nature of the ceramics whereby the grain boundaries act as Josephson type junctions, inherently limiting critical currents. Third is the weak flux pinning observed in these materials which could severly limit their applicability in high magnetic fields. All of these problems will necessitate the development of new processing technologies which optimize the materials properties for the various applications. Because of the differences in the materials properties in the $\mathrm{Y}-\mathrm{Ba}-\mathrm{Cu}-\mathrm{O}, \mathrm{Bi}-\mathrm{Sr}-\mathrm{Ca}-\mathrm{Cu}-\mathrm{O}$ and $\mathrm{Tl}-\mathrm{Ca}-\mathrm{Ba}-\mathrm{Cu}-\mathrm{O}$ systems, the processing technologies will probably be materials specific. This is especially true of the $\mathrm{YBa}_{2} \mathrm{Cu}_{3} \mathrm{O}_{7}$ material which has a phase change and oxygen equilibrium problems in the processing range of interest, but is the most highly pinned of the current superconductors with $\mathrm{Tc}>$ $77 \mathrm{~K} .[1]$

In this paper we investigate two different processing techniques which seem particularly well suited to a particular materials system. Data will be presented for the rapid thermal processing [2-4] of melt spun $\mathrm{YBa}_{2} \mathrm{Cu}_{3} \mathrm{O}_{7}(\mathrm{Y}-123)$ fibers [5] and for the mechanical extrusion and cold rolling followed by extended thermal anneals for $\mathrm{Ag}$ sheathed wires in the $\mathrm{Bi}(\mathrm{Pb})-\mathrm{Sr}-\mathrm{Ca}$ $\mathrm{Cu}-\mathrm{O}$ system [6,7]. Rapid thermal processing (RTP) of melt spun (Y-123) fibers has yielded wires with $\mathrm{T}_{\mathrm{c}, \mathrm{x}=0}$ of up to $92 \mathrm{~K}$ and $\mathrm{J}_{\mathrm{c}}$ to $1100 \mathrm{~A} / \mathrm{cm}^{2}$. We have examined the kinetics of the processes involved and investigated the dependence of the sample morphology on a two dimensional matrix of time and temperature for RTP. Surprisingly, after a 1 second $1025^{\circ} \mathrm{C}$ RTP under $\mathrm{O}_{2}$, fibers that were made from stoichiometric tetragonal $\mathrm{YBa}_{2} \mathrm{Cu}_{3} \mathrm{O}_{6}$ are orthorhombic, show the normal twin structure of fully processed $Y-123$ and have $a T_{c, R=0}$ of $88 \mathrm{~K}$. TEM examination has also shown the material to be quite uniform across the diameter of the sample [8]. 


\section{DISCLAIMER}

This report was prepared as an account of work sponsored by an agency of the United States Government. Neither the United States Government nor any agency Thereof, nor any of their employees, makes any warranty, express or implied, or assumes any legal liability or responsibility for the accuracy, completeness, or usefulness of any information, apparatus, product, or process disclosed, or represents that its use would not infringe privately owned rights. Reference herein to any specific commercial product, process, or service by trade name, trademark, manufacturer, or otherwise does not necessarily constitute or imply its endorsement, recommendation, or favoring by the United States Government or any agency thereof. The views and opinions of authors expressed herein do not necessarily state or reflect those of the United States Government or any agency thereof. 


\section{DISCLAIMER}

Portions of this document may be illegible in electronic image products. Images are produced from the best available original document. 


\section{DISCLAIMER}

This report was prepared as an account of work sponsored by an agency of the United States Government. Neither the United States Government nor any agency thereof, nor any of their employees, makes any warranty, express or implied, or assumes any legal liability or responsibility for the accuracy, completeness, or usefulness of any information, apparatus, product, or process disclosed, or represents that its use would not infringe privately owned rights. Reference herein to any specific commercial product, process, or service by trade name, trademark, manufacturer, or otherwise does not necessarily constitute or imply its endorsement, recommendation, or favoring by the United States Government or any agency thereof. The views and opinions of authors expressed herein do not necessarily state or reflect those of the United States Government or any agency thereof. 
state resistivities between 1 and $2 \mathrm{~m} \Omega$-cm is observed with RTP from 950 to $1050^{\circ} \mathrm{C}$. There appears to be a complex relationship between RTP time and temperature and the stoichiometry of the ceramic whereby longer anneals at low temperatures produce morphologies identical to those of shorter anneals at higher temperatures, but with different chemistries. This introduces the possibility of tuning the process so as to produce the optimum morphology and grain boundary chemistry, which will be critical to obtaining high critical currents in this system.

Recent results by a number of groups in Japan suggest that mechanical reprocessing HTS materials in the $\mathrm{Bi}(\mathrm{Pb})-\mathrm{Sr}-\mathrm{Ca}-\mathrm{Cu}-\mathrm{O}$ system followed by extensive annealing produces materials with $T_{c}$ 's to $110 \mathrm{~K}$ and promising critical currents in a field $[8,9]$. We have produced

$\mathrm{Bi}$-HTS tapes from $\mathrm{Bi}_{1.7} \mathrm{~Pb}_{0.3} \mathrm{Sr}_{2} \mathrm{Ca}_{2} \mathrm{Cu}_{3} \mathrm{O}_{10}$ bulk ceramics that have been encapsulated in $\mathrm{Ag}$, cold rolled and then thermally annealed at $\sim 850^{\circ} \mathrm{C}$ for up to $150 \mathrm{hr}$. These tapes show zero resistance to $100 \mathrm{~K}$, are highly c-axis oriented (a-b random) and show improved magnetic hysteresis at temperatures above where the flux lattice is reported to melt. Critical currents, however, are poor and the transport measurements indicate weak link dominated transport. These results show that the $\mathrm{Bi}-\mathrm{Sr}-\mathrm{Ca}-\mathrm{Cu}-\mathrm{O}$ system behaves quite differently from the $\mathrm{Tl}-\mathrm{Ca}$ $\mathrm{Ba}-\mathrm{Cu}-\mathrm{O}$ and $\mathrm{Y}-\mathrm{Ba}-\mathrm{Cu}$ materials with respect to superconducting properties after mechanical deformation and extended thermal processing.

\section{Materials Processing}

$\mathrm{YBa}_{2} \mathrm{Cu}_{3} \mathrm{O}_{4}$ RTP Fibers

Green Fiber Synthesis

Fibers were produced from superconducting powders of stoichiometric $\mathrm{YBa}_{2} \mathrm{Cu}_{3} \mathrm{O}_{7-\mathrm{x}}$ prepared by solid state reaction in air or $\mathrm{YBa}_{2} \mathrm{Cu}_{3} \mathrm{O}_{7 . x}$ with $5 \mathrm{wt} \% \mathrm{CuO}$. Fine powder was prepared by jet milling the calcined material to produce an average particle size of $3.7 \mu \mathrm{m}$. Some powders were mechanically milled to $1.6 \mu \mathrm{m}$. The fibers were produced using a proprietary fiber spinning process in which HTS powders (as above) are combined with a resin so that it can be spun to any length on the conventional textile fiber spinning machines. These fibers are quite tractable in their green or unfired state and can be braided to produce the filament architecture necessary to control AC losses. Seven fibers from a stoichiometric Y-123 powder of $1.6 \mu \mathrm{m}$ particle size were also braided in this fashion and processed in the braided form.

\section{Eiber Burn Out}

The organic binders were removed from the green fibers by an air anneal at $500^{\circ} \mathrm{C}$ with the fibers supported on a high purity alumina plate. The furnace was ramped to $500^{\circ} \mathrm{C}$ from room temperature at $20^{\circ} \mathrm{C} / \mathrm{min}$, held there for $10 \mathrm{~min}$., and cooled to room temperature at 10 ${ }^{\circ} \mathrm{C} / \mathrm{min}$. Figures 1A illustrates the morphology of the 5\% CuO-rich fiber at this stage: angular grains $1-10 \mu \mathrm{m}$ in size and little or no intergranular connections. The fiber diameters were approximately $300 \mu \mathrm{m}$ for the stoichiometric fibers and $150 \mu \mathrm{m}$ for the CuO-rich fibers. The fibers were quite fragile at this stage, suggesting little sintering. The Y-123 is probably oxygen deficient due to the well established oxygen loss during the air anneal. Magnetization confirms low diamagnetic shielding fractions in the burned out fibers. The woven braid was burned out by ramping to $500^{\circ} \mathrm{C}$ at $4^{\circ} \mathrm{C} / \mathrm{min}$ followed by heating in nitrogen for 2 hours at $500^{\circ} \mathrm{C}$ followed by 1 hour at $500^{\circ} \mathrm{C}$ in air. 
Theburned out fibers were sintered on a 4 " $\mathrm{Si}$ wafer coated with $1 \mu \mathrm{m}$ of $\mathrm{Si}_{3} \mathrm{~N}_{4}$ in an ADDAX-AET model R-1000 rapid thermal annealer equipped with a mass flow controlled gas inlet manifold. The system was equipped with two low mass thermocouples with one or both in direct contact with the fiber or fibers to be annealed. Before each run the system (100 cc chamber volume) was purged with high purity oxygen for 10 seconds. The oxygen purge was continued for the entire run at 3 liters/sec and was terminated $10 \mathrm{sec}$ after the programmed run had been completed. Typical run conditions (all under $1 \mathrm{~atm}$. of oxygen) were a 10 second wait period followed by a 4 second ramp to the sintering temperature, holding at that temperature for 1 second, and then a cooling ramp to $600^{\circ} \mathrm{C}$ (typically 96 seconds) followed by a ramp to room temperature (typically 180 seconds). Typically the agreement between the programmed temperature and the measured temperature was better than $1 \%$ except below $300^{\circ} \mathrm{C}$ where the cooling from the oxygen flow and radiative losses could not keep up with the program and variances to $>25 \%$ were observed. Samples were typically removed from the chamber when they reached $100^{\circ} \mathrm{C}$. At temperatures above $1075^{\circ} \mathrm{C}$ the fibers began to react significantly with the substrate, making their removal difficult. This was especially true of the CuOrich fibers. Fibers were characterized in the as-fired condition with no oxygen anneal. Oxygen anneals, though not discussed here, did improve the superconducting properties of the wires in some cases. The optimal processing temperature was found to be $1025^{\circ} \mathrm{C}$ for the stoichiometric wires and $1000^{\circ} \mathrm{C}$ for the CuO-rich wires based upon the sintering observed in the fiber, the $\mathrm{x}$ ray diffraction phase purity and a transition temperature of $>88 \mathrm{~K}$. The braid was processed at $1025^{\circ} \mathrm{C}$ for $2-5 \mathrm{sec}$.

Figure 1 illustrates typical micrographs for the CuO-rich wires processed for 1 second from $975^{\circ} \mathrm{C}$ to $1075^{\circ} \mathrm{C}$ in $25^{\circ} \mathrm{C}$ increments (B-F). The fibers show increasing grain size to $1050^{\circ} \mathrm{C}$ after which decomposition is observed with the typical elongated grain structure. The processing to $1050^{\circ} \mathrm{C}$ shows uniform melting with considerable grain growth indicative of substantial liquid phase formation and sintering. The wire processed at $1075^{\circ} \mathrm{C}$ shows extreme grain growth with a very non-uniform morphology. The presence of plate-like growths is indicative of extensive liquid phase sintering. This is supported by the energy dispersive $x$-ray analysis which shows essentially only stoichiometric $\mathrm{Y}-123$ uniformly throughout the fibers processed below $1075^{\circ} \mathrm{C}$, while the fiber processed at $1075^{\circ} \mathrm{C}$ shows localized regions of $\mathrm{Y}$ 123 and regions that are off stoichiometry indicative of the presence of impurity phases. The stoichiometric fibers show a nearly identical change in morphology with RTP temperature, but each change occurs $25^{\circ} \mathrm{C}$ higher in temperature. Detailed examination of optical micrographs of polished, CuO-rich fibers show that they sinter to near full density and have small amounts of a primarily $\mathrm{CuO}$ intergranular phase that increases in proportion to the initial amount of $\mathrm{CuO}$ in the fiber. The stoichiometric fibers show two minor phases; a surface intergranular phase that may be $\mathrm{CuO}$ and inclusions in the bulk that are probably $\mathrm{Y}_{2} \mathrm{BaCuO}_{5}$.

The fibers had excellent shape retention during the RTP. Single fibers remained round in cross-section and quite straight if constrained during RTP. Even multifilamentary braided fibers had good shape retention. The shape and identity of the individual fibers are maintained.

\section{Ag Sheathed Bi Wires}

$\mathrm{Bi}_{1.7} \mathrm{~Pb}_{0.3} \mathrm{Sr}_{2} \mathrm{Ca}_{2} \mathrm{Cu}_{3} \mathrm{O}_{10}$ bulk ceramics were prepared by sintering pressed pellets of high 


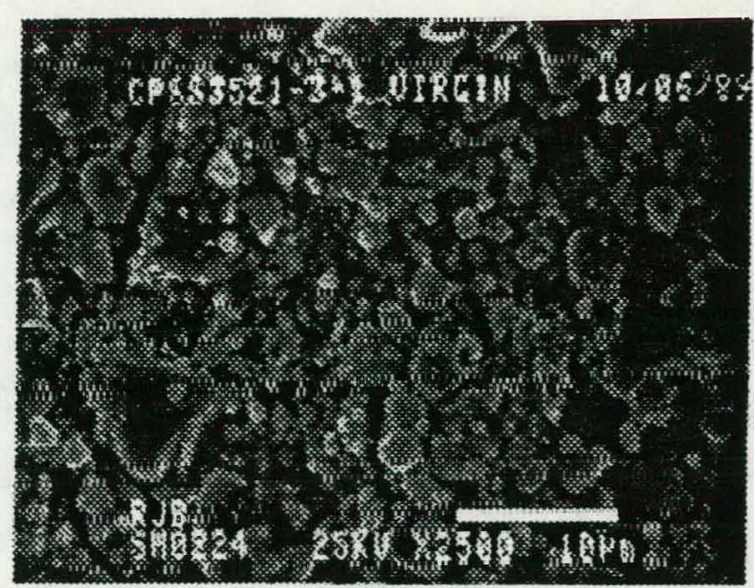

(A)

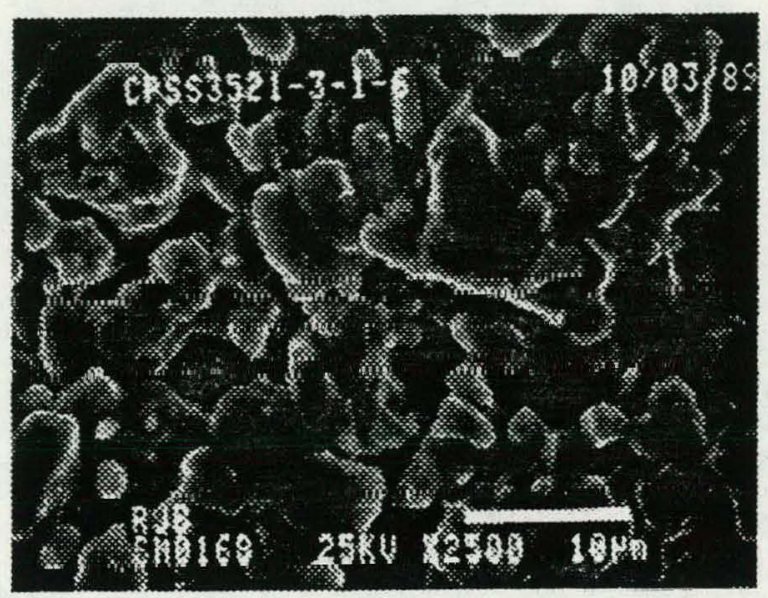

\section{(C)}

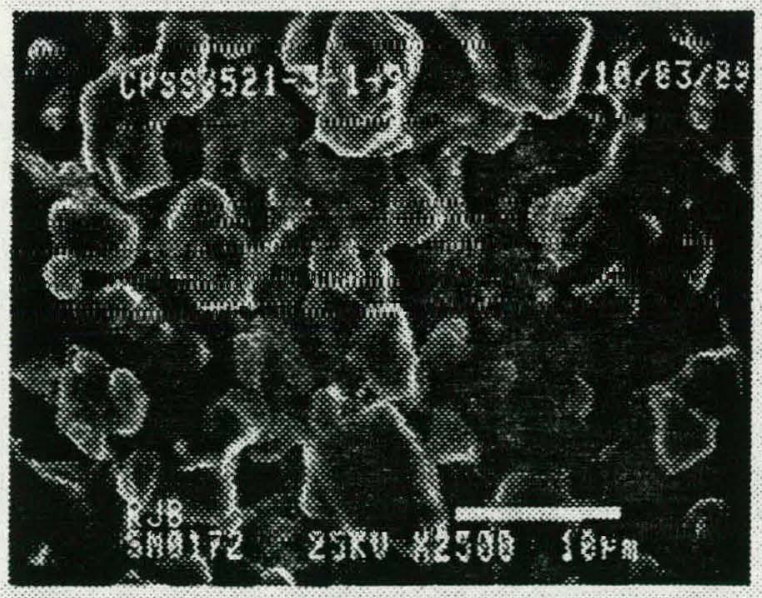

(E)

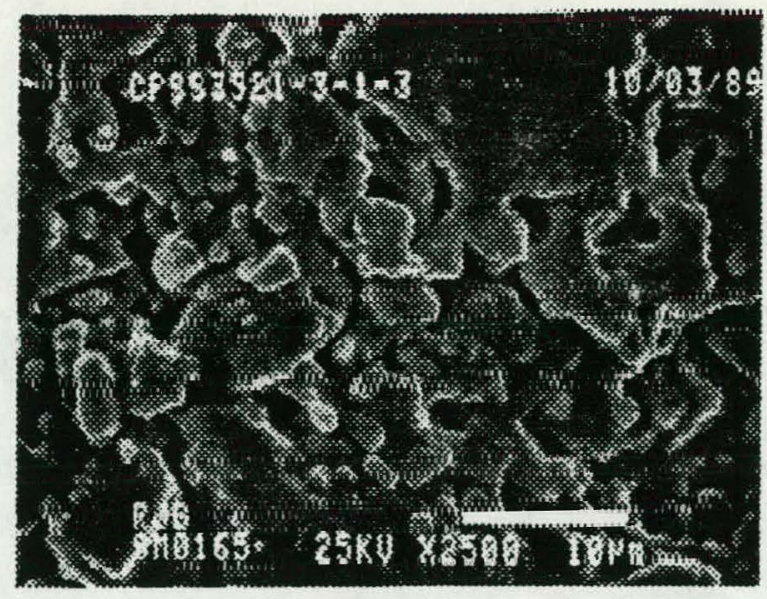

(B)

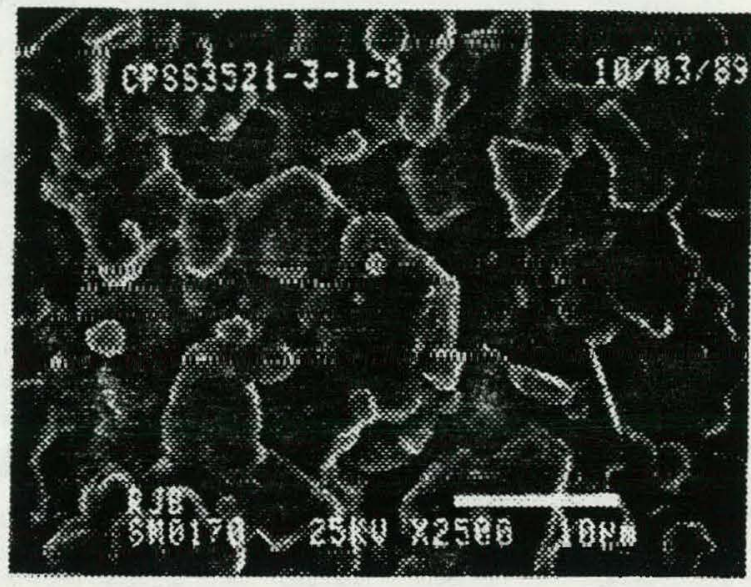

(D)

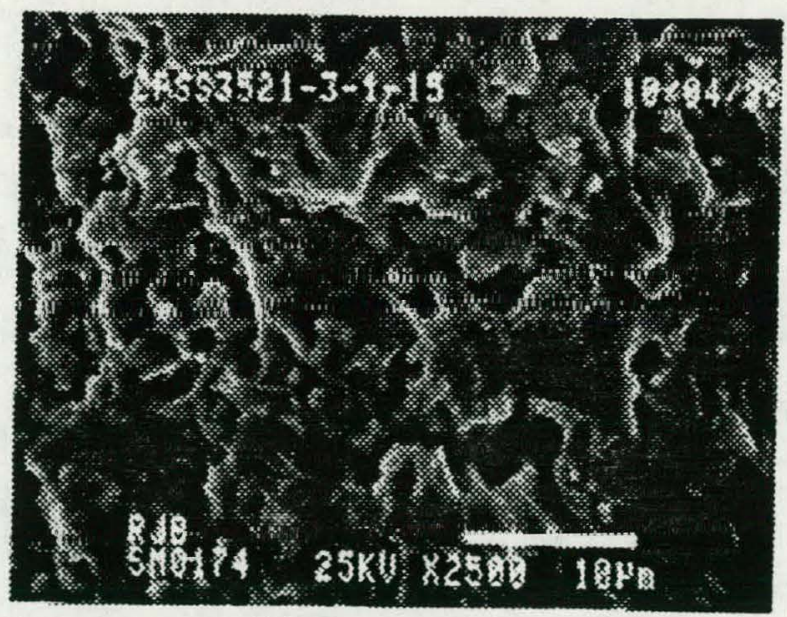

(F)

Figure 1. Scanning electron micrograph of (A) virgin burned out $5 \% \mathrm{CuO}$ rich fiber, (B) fiber as in (A) after a 1 second RTP at $975^{\circ} \mathrm{C}$, (C) fiber as in (A) after a 1 second RTP at $1000^{\circ} \mathrm{C}$, (D) fiber as in (A) after a 1 second RTP at $1025^{\circ} \mathrm{C}(\mathrm{E})$ fiber as in (A) after a 1 second RTP at $1050^{\circ} \mathrm{C}$ and (F) fiber as in (A) after a 1 second RTP at $1075^{\circ} \mathrm{C}$. All RTP runs were done under 1 atmosphere of oxygen with $-4 \mathrm{~min}$. cool down to $100^{\circ} \mathrm{C}$. 
purity mixed oxides and regrinding, pressing and resintering (same conditions), where all sintering was done at $850^{\circ} \mathrm{C}$ for 12 hours in the air. Two approaches were employed to make tapes. Bulk ceramic was ground and packed in silver tubes $100 \mathrm{~mm}$ long x $6 \mathrm{~mm}$ OD-4mm ID, a silver plug was inserted and the tubes were sent to Supercon for extrusion and wire drawing to $1 \mathrm{~mm}$ OD. These tapes, now over $2 \mathrm{~m}$ in length, were then cold rolled at Sandia to roughly $0.5 \mathrm{~mm}$ thickness. Other tapes were prepared by cutting thin slices from the pellet $(2 \times 2 \times 20$ $\mathrm{mm}$ ), double wrapping them in Ag foil and cold rolling. These tapes were otherwize handled identically to the drawn tapes. In these tapes the silver foil could be removed after processing and the superconductor examined directly. All of the tapes were then annealed in air for 80 hours at temperatures between 820 and $870^{\circ} \mathrm{C}$. Melting occurred above $850^{\circ} \mathrm{C}$ in some of the tapes causing a loss of superconductor from the Ag. Some of these tapes were then rolled again to between 0.2 and $0.4 \mathrm{~mm}$ and annealed for 50 hours at $840^{\circ} \mathrm{C}$. The tapes with the wrapping of $\mathrm{Ag}$ foil had a higher width to thickness ratio (10:1) than did the drawn tapes (2-3:1) after rolling, leading to a very-plate like morphology as is shown in Figure 2.

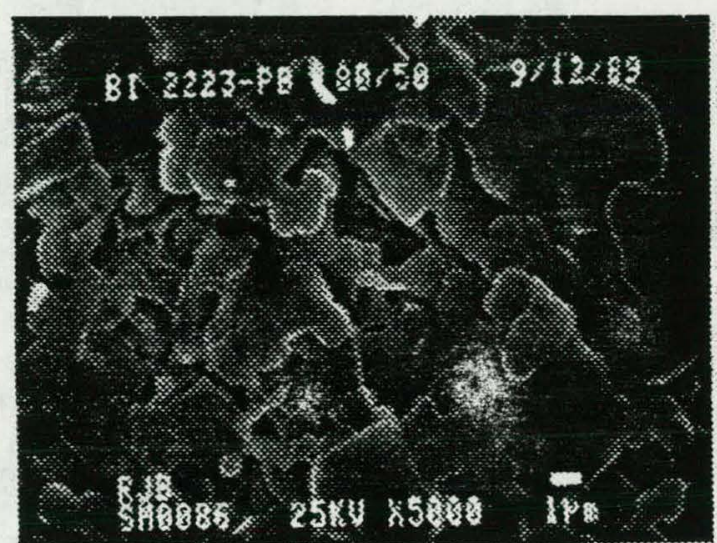

Figure 2. Scanning electron micrograph of the morphology of the cold rolled and annealed $\mathrm{Ag}$ sheathed $\mathrm{Bi}_{1.7} \mathrm{~Pb}_{03} \mathrm{~S}_{2} \mathrm{Ca}_{2} \mathrm{Cu}_{3} \mathrm{O}_{10-x}$ tape.

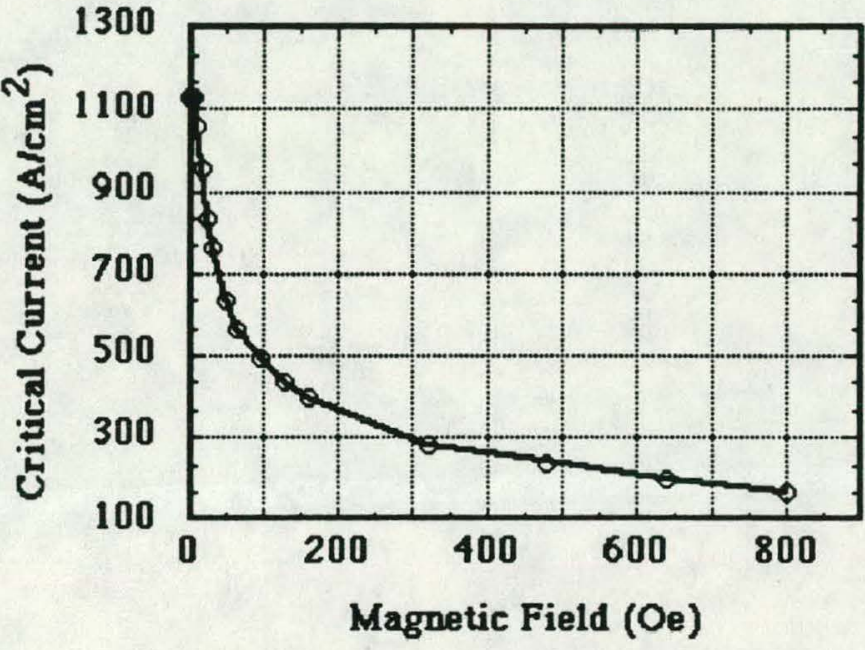

Figure 3. Critical current density at 76 Kversus field to 800 Oefor a 5\% CuO-rich fiber after RTP for 1 second at $1000^{\circ} \mathrm{C}$.

\section{Results and Discussion}

In the section below we will present structure, morphology, magnetization and transport results, first for the RTP Y-123 and then the Bi tapes. Finally we will summarize the results relating the two processing techniques.

\section{$\mathrm{YBa}_{2} \mathrm{Cu}_{2} \mathrm{O}$, RTP Fibers}

Despite the short time at temperature and the rapid cool down, fibers that were initially oxygen deficient or fully oxygenated show transport and magnetization properties typical of high quality bulk ceramic $\mathrm{YBa}_{2} \mathrm{Cu}_{3} \mathrm{O}_{7}$. Zero resistance is observed between 88 and $92 \mathrm{~K}$ for virtually all the materials examined and the normal state resistances vary from $1-10 \mathrm{~m} \Omega-\mathrm{cm}$. This high normal state resistivity is typically indicative of weak linked materials[10]. Interestingly, the CuO-rich materials tend to have lower normal state resistivities than the stoichiometric materials indicating that the $\mathrm{CuO}$ acts as or generates a flux which produces better boundaries. The RTP versus composition data support this. Higher $\mathrm{CuO}$ contents produce large grains 
and elongated grain growth at lower temperatures. The decomposition temperature drops from $1075^{\circ} \mathrm{C}$ for the stoichiometric material to $1000^{\circ} \mathrm{C}$ for the $10 \% \mathrm{CuO}$-rich material. The critical current results reflect the $R$ vs $T$ data in that the stoichiometric materials show essentially no critical current $\left(<10 \mathrm{~A} / \mathrm{cm}^{2}\right)$ indicative of a highly weak linked structure. Figure 3 illustrates the transport critical current density $\mathrm{J}_{\mathrm{a}}$ at $76 \mathrm{~K}$ vs field for a $5 \% \mathrm{CuO}$-rich wire. The maximum $J_{\mathfrak{a}}$ is $1100 \mathrm{~A} / \mathrm{cm}^{2}$ and falls rapidly in the applied field to 800 Gauss. This behavior is typical for weak linked Y-123 bulk ceramic materials.

Figure 4 compares diamagnetic shielding and Meissner effect data in two wires after identical RTP runs ( $4 \mathrm{sec}$. ramp to $1000^{\circ} \mathrm{C}, 1 \mathrm{sec}$. hold, and a cooling ramp as described above), one wire with stoichiometric Y-123 starting composition (solid triangles) and the other with 5\% excess $\mathrm{CuO}$ (open triangles). Both wires exhibit strong diamagnetic shielding at $5 \mathrm{~K}$ which persists to $92 \mathrm{~K}$ ( $\mathrm{T}_{\mathrm{c}}$ for $\mathrm{Y}-123$ ), but the stoichiometric wire loses $90 \%$ of the low temperature shielding between 20 and $55 \mathrm{~K}$. In contrast, the CuO-rich wire loses the shielding response only above $80 \mathrm{~K}$ where the applied field $\left(25 \mathrm{Oe}\right.$ ) exceeds the lower critical field $\mathrm{H}_{\mathrm{cl}}$. The CuOrich wire exhibits a sharp onset of superconductivity at $92 \mathrm{~K}$, and the low temperature Meissner signal is $1 / 3$ of the shielding value. The shielding/Meissner ratio at $5 \mathrm{~K}$ is typically 1.5 to 2.0 for sintered ceramic Y-123 in $25 \mathrm{Oe}$, so the ratio of 3.0 for the CuO-rich fiber suggests slightly stronger flux pinning. In contrast, the Meissner signal in the stoichiometric fiber begins at 92 $\mathrm{K}$, but shows a very broad transition, rising nearly linearly with decreasing temperature down to $40 \mathrm{~K}$. The shielding/Meissner ratio is an anomalously high 13 for the stoichiometric wire.

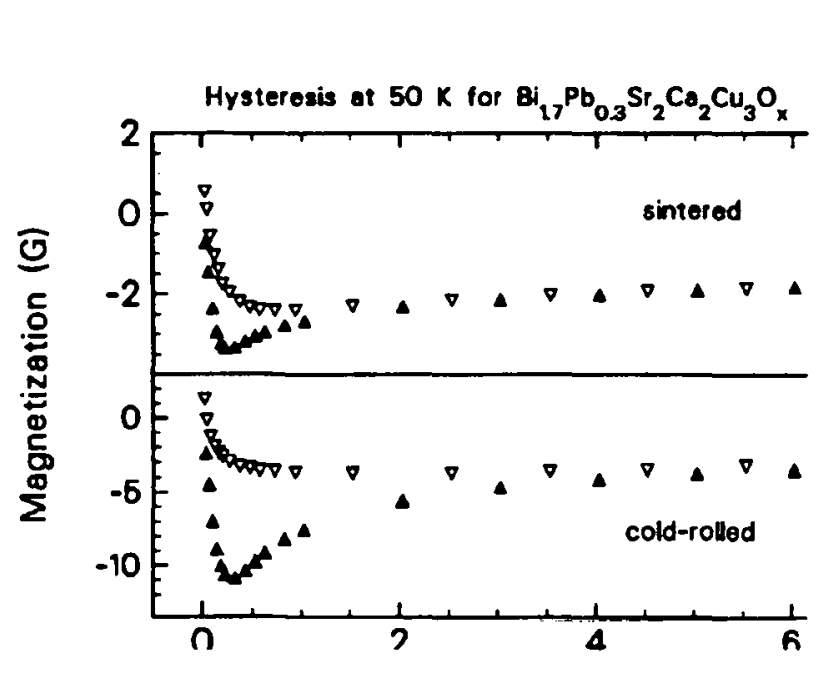

Figure 4. Diamagnetic shielding versus increasing temperature (top) and Meissner effect versus decreasing temperature (bottom) in 25 Oe for identically processed RTP wires $\left(1000^{\circ} \mathrm{C}\right.$ for $\left.1 \mathrm{sec}\right)$ with stoichiometric (solid triangles) and 5\% CuO-rich (open triangles) starting compositions.

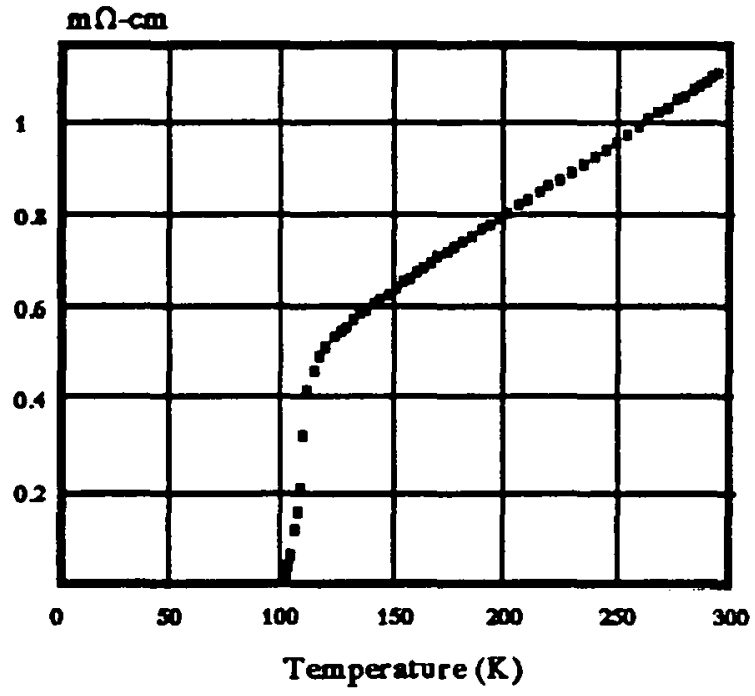

Figure 5. Resistivity versus temperature for a Bil.7Pb0.3Sr2Ca2Cu3O10-x tape after cold rolling and an 80 hour $850^{\circ} \mathrm{C}$ anneal.

The rapid decrease in shielding between 20 and $55 \mathrm{~K}$ is a combination of two detrimental effects, the presence of grains with low $T_{c}$ 's due to compositional (including oxygen) problems and the loss of macroscopic shielding current paths in 25 Oe due to extreme weak link behavior also observer in the transport data. The shielding at $5 \mathrm{~K}$ in the stoichiometric wire is 75\% of the value in the CuO-rich wire because the impurity phases in the interior of the stoichiometric wire are "hidden" by the screening currents near the wire surface. As the current through the weak links falls with increasing temperature, flux penetrates the interior of the fiber, exposing the impurity phases and the off-stoichiometric grains with lower $T_{c}$ 's which 
results in a rapid decrease in the shielding signal. In contrast, the Meissner signals in in the lower portion of Figure 4 reflect the "true" superconducting fraction of the wires, except for differences in flux pinning due to the differing numbers of defects and impurity phases in the two wires.

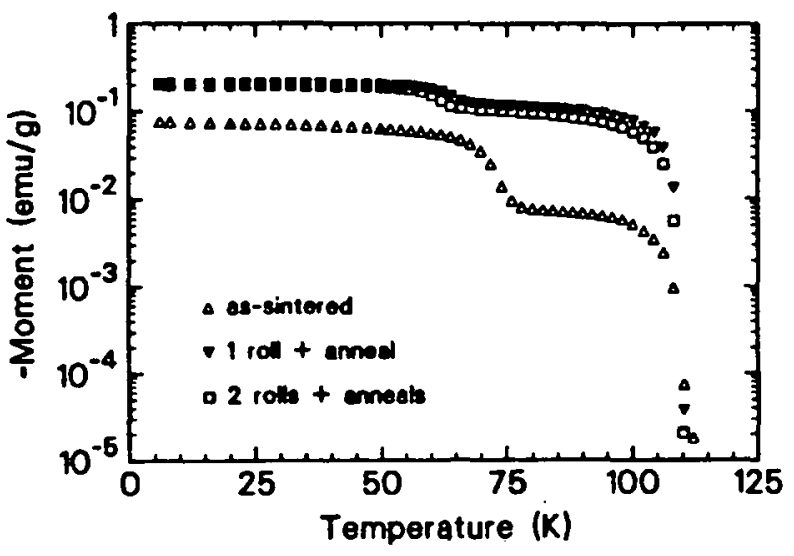

Figure 6. Comparison of Meissner data in $25 \mathrm{Oe}$ versus decreasing temperature for Bil.7Pb0.3Sr2Ca2Cu3O10-x bulk ceramic; tape from this ceramic that was cold rolled and annealed for 80 hours at $850^{\circ} \mathrm{C}$; and the 80 hour tape after additional cold rolling and a 50 hour anneal at $850^{\circ} \mathrm{C}$.

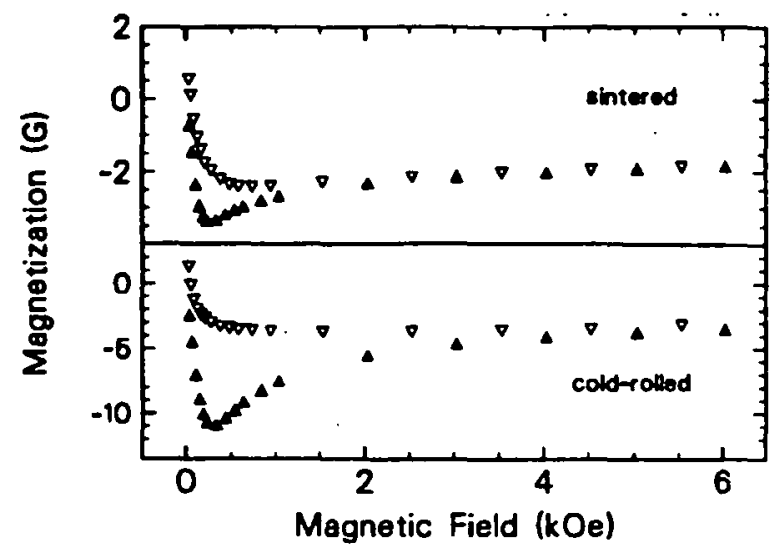

Figure 7. Magnetic hysteresis loops for the bulk ceramic Bil.7Pb0.3Sr2Ca2Cu3O10-x and the tape that was annealed at $850^{\circ} \mathrm{C}$ for 80 hours.

\section{Ag Sheathed Bi-Sr-Ca-Cu-O Wires}

After cold rolling and annealing the superconducting phase had a plate-like morphology with grains 10-20 microns in size, which x-ray diffraction showed to be highly oriented with the c-axis normal to the rolling plane. This is the optimum orientation for transport in the tapes. The resistivity vs. temperature for the best $\mathrm{Pb}$ doped sample is shown in Figure $5, \mathrm{~T}_{\mathrm{cR}=0}$ is $100 \mathrm{~K}$ after the first anneal $\left(80\right.$ hours at $\left.850^{\circ} \mathrm{C}\right) ; \mathrm{T}_{c \mathrm{R}=0}$ was $95 \mathrm{~K}$ after a scond anneal for 50 hours at $850^{\circ} \mathrm{C}$ indicating some deterioration. Preliminary critical current measurements have shown $\mathrm{J}_{c}$ 's on the order of 100 's of $\mathrm{A} / \mathrm{cm}^{2}$ and weak link character. This is reflected as well in the static magnetization, Figure 6, where the Meissner onset occurs at $110 \mathrm{~K}$; there is a significant increase in the amount of high temperature phase after the first processing cycle and a slight decrease after the second cycle. Figure 8 compares hysteresis loops for two samples from Figure 6, showing increased pinning at $50 \mathrm{~K}$ in the mechanically processed and annealed tape. This temperature is above the flux lattice melting point and may indicate that at least some of the defects introduced during processing are pinning sites [11,12]. That they still are present after such extensive anneals is very encouraging. Current work centers on optimizing the rolling and annealing process and exploring the effects of composition changes. Recent results on bulk ceramic $\mathrm{Bi}_{1.7} \mathrm{~Pb}_{0.3} \mathrm{Sr}_{2} \mathrm{Ca}_{2} \mathrm{Cu}_{3} \mathrm{O}_{10-\mathrm{x}}$ indicates that substantial increases in the amount of the high temperature phase occurs upon extended annealing of pressed pellets at $850^{\circ} \mathrm{C}$ for 80 hours. The pinning in this material is currently being examined.

\section{Summary}

The major goal of conductor processing is to produce mechanically strong HTS wires and tapes that have high critical currents in large magnetic fields. Clearly, this goal has not been met to date in any laboratory. However, the present results indicate that a number of approaches provide a viable means to this end. The major issues are to produce high quality 
grains, strong linked grain boundaries, high pinning center densities and a mechanically robust ceramic. In the present study techniques have been developed that fulfill some of these objectives. Both types of processs have produced high quality grains and ceramics with a high degree of mechanical integrity. The RTP results indicate that the production of a liquid CuO-rich flux can greatly influence the grain boundary properties. This is similar to the case in the Tl-Ca-Ba$\mathrm{Cu}-\mathrm{O}$ thin films where liquid flux growth produces strong link behavior [13]. At higher temperatures the $\mathrm{CuO}$ flux also appears to produce elongated grains and some degree of oriented growth. The Bi-Sr-Ca-Cu-O tape results indicate that pinning centers with increased thermodynamic stabilty can be introduced by mechanical deformation and that these centers are stable during extended anneals at $850^{\circ} \mathrm{C}$. The grains in these tapes show a high degree of orientation that will be crucial to minimizing the effects of anisotropic conduction on intergranular transport. In the Bi system the $\mathrm{Pb}$ appears to stabilize of the high temperature $110 \mathrm{~K}$ phase and/or act as a flux to produce the high temperature phase. The origin of the benefits of the extended anneals is not currently understood. Overall it appears that optimum materials will employ liquid phase sintering after mechanical processing to provide pinning centers and grain orientation.

\section{Acknowledgements}

This work at Sandia National Laboratories was supported, in part, by the United States Department of Energy, Office of Basic Energy Sciences, under Contract No. DE-AC0476DP00789. The technical assistance of R. P. Hellmer, T. Castillo and G. Pannell, Jr. is gratefully acknowledged.

\section{References}

1. Y. Yeshurun, A. P. Malozemoff, Cryogenics, 29, 258(1989).

2. T. O. Sedgwick, "Rapid Thermal Processing: How Well Is It Doing and Where Is It Going?" Materials Research Society, Symposia Proceedings Volume 92.

3. M. J. Hart and A. G. R. Evans, Semicond. Sci. Technol., 3, 421(1988).

5. D. S. Ginley, E. L. Venturini, J. F. Kwak, M. Mitchell, B. Morosin, R. J. Baughman, J. W. Halloran and M. J. Neal, J. Applied Physics, (submitted).

6. E. Takayama-Muromachi, Y. Uchida, Y. Matsui, M. Onoda and K. Kato, Jpn. J. Appl. Phys., 27, L556(1988)

7. M. Takano, J. Takada, K. Oda, H. Kitaguchi, Y. Miura, Y. Ikeda, Y. Tomii and H. Mazaki, Jpn. J. Appl. Phys., 27, L1041(1988).

8. S. Basu, T. E. Mitchell, J. W. Halloran, M. J. Neal, D. S. Ginley, M. A. Mitchell, R. J. Baughman, E. L. Venturini, J. F. Kwak and B. Morosin, in preparation.

9. T. Asano, Y. Tanaka, M. Fukutomi, K. Jikihara, J. Machida, and H. Maeda, Jpn. J. Appl. Phys., 27, L1652(1988).

10. J. F. Kwak, E. L. Venturini, R. J. Baughman, B. Morosin, and D. S. Ginley, Physica C 156, 103(1988): and Cryogenics, accepted.

11. E. L. Venturini, J. F. Kwak, D. S. Ginley, B. Morosin and R. J. Baughman, Proceedings of Conf. on The Science and Technology of Thin Film Superconductors,(Plenum, New York) R. McConnell ed., Nov. 1988, Colorado Springs, CO page 395.

12. H. Kumakura, K. Togano, E. Yanagisawa, and H. Maeda, Appl. Phys. Lett., 55, 185(1989).

13. D. S. Ginley, J. F. Kwak, E. L. Venturini, B. Morosin, and R. J. Baughman, Physica C Superconductivity, 160, 42(1989). 